\title{
Analyzing Information Needs of Elderly People: A Survey in Chinese Rural Community
}

\author{
Chunfang Zou', Ping Zhou ${ }^{2,3}$ \\ ${ }^{1}$ School of business administration, Jiangxi University of Finance and Economics, Nanchang, China \\ ${ }^{2}$ School of Information Technology, Jiangxi University of Finance and Economics, Nanchang, China \\ ${ }^{3}$ Jiangxi Key Laboratory of Data and Knowledge Engineering, Jiangxi University of Finance and Economics, \\ Nanchang, China \\ Email: zou.spring@163.com, zp jx@126.com
}

Received $* * * * 2014$

\begin{abstract}
A survey about the information needs of elderly people could find out the information required to address the needs of the aged in a community. Analyzing data collected from 600 elderly people through field investigation with a questionnaire in a rural community in central China, the results show that the preferred information format of the majority of aged people is audio and/or visual information product, especially audio product. Most of the aged people stated that they were in need of healthy and medical non-educational audio information products. The survey maybe lead to improved and expanded information services for respondents who are short of such services, including Public broadcasting services, extending the audiovisual collection, loaning audiovisuals, religious faith audiovisuals and others providing needed information to them. In summary, this paper assembles views on what the elderly people currently need to be helped by both practitioners and researchers in the elderly people services domain.
\end{abstract}

\section{Keywords}

Information Needs, Elderly People, Chinese Rural Community

\section{Introduction}

The information needs of the elderly population, particularly in rural areas, have scarcely been investigated by researchers and are very poorly covered in the literatures of information science. Many researchers and commentators over the past three decades have noted a lack of investigation in these areas and consequent exiguous knowledge about this kind of topic. Zuo meiyun, Liu qingqing and Liu fang (2009) [1], Jiang lihua, Huang jiacheng (2011) [2] and Zhu xiujie (2012) [3] draw attention either to how little be known about such needs or to the necessity of learning more. Meager coverage in the related literatures should not obscure the importance of research on elderly’ information needs in rural district, especially in terms of its contribution towards a more ef- 
fective tailoring of the content of information services and systems to meet the elderly people's requirements.

The target population in this research is the elderly people in Chinese rural community. According to the forecast reports of the United Nations "the forecast of world population (1998)", by year 2000, more than $10.1 \%$ of population in China will be over age 60; by 2020, it will reach $16.6 \%$ and by 2050 to $29.7 \%$.The proportion of people with over age 65 in 2000 was $6.8 \%$, will reach $11.5 \%$ by 2020, to $22.6 \%$ in 2050 [4]. The number and proportion of older adults in China during year 2000 to 2050 are showed in Table 1.

Care of the elderly is one of the most important aspects of primary health care [5]. In order to increase the safety needs and love needs of an elderly social stratum, proper concerns in the economic, political and social efforts are necessary, so concerning for the elderly people represents a great responsibility for education of the progeny of this community. Religious teachings are often used to reinforce and support the cultural imperatives of caring for the elderly [6]. Psychic sanity and knowledge promotion and scientific mastery of elderly people in the rural community affect the progression or retardation of society [7].

The main objective of this survey is to know the information needs of the elderly people in the rural community in China which is experiencing a rapid growth of its elderly population. The paper is structured as follows. Section 2 reviews related literature works. Section 3 and section 4 describe the research design and analyzes the results of the survey respectively. In section 5 and section 6 , discussion and conclusions are given singly.

\section{Literature Review}

The study of rural community, since the earliest times of year 1881, has been considered and observed in sociological books, the history of counties and different regions of the world [8]. Most of the previous studies on this populace concern only their tradition and conventions; however, the paucity of institutions, facilities and specialist manpower for taking care of elderly people lead to that their information needs have not yet been surveyed sufficiently. Current trends at all levels suggest an increasing demand and emphasis on keeping a watchful eye on the elderly [9]. This is because of the increasing number of elderly people in our population and the high proportion of migration of young people from rural to urban areas to seek employment due to lack of public infrastructure service and low level of income in vast majority of rural areas. Old people's houses built with the support of local government represent the only institutional care for elderly people at the present time [10]. Some of the crucial issues in meeting the information needs of the elderly, which include the attitude of information providers towards care for the elderly, where information providers would prefer to meet for the elderly, the types of information being needed by the elderly, and the effects of meeting for the elderly on information providers, etc have not been properly figured out.

There are some issues that this study will inform. These issues are particularly important in Chinese culture, because taking good care of the elderly is the fine tradition of our Chinese nation and has been undertaken by the government and extended by family system for so many years.

Zuo meiyun, Liu qingqing and Liu fang (2009) [1] who based on the Maslow's theory of hierarchy of needs and literary study analyzed the needs of the elderly and designed a model of the elderly's information needs. Given the above analysis, they discussed the implications of applying the model and pointed out the information technology/information system (IT/IS) products' positive roles in benefit to the elderly's information needs. On

Table 1. The proportion of older adults in China by 2000-2050 (source: [11]).

\begin{tabular}{|c|c|c|c|c|c|c|c|}
\hline \multirow{2}{*}{ year } & \multirow{2}{*}{ total(hundred million) } & \multicolumn{2}{|c|}{ Age > 60 (years) } & \multicolumn{2}{|c|}{ Age > 65 (years) } & \multicolumn{2}{|c|}{ Age > 80 (years) } \\
\hline & & number & proportion & number & proportion & number & proportion \\
\hline 2000 & 12.7 & 1.31 & 10.31 & 0.91 & 7.17 & 0.14 & 1.10 \\
\hline 2010 & 13.76 & 1.73 & 12.57 & 1.15 & 8.36 & 0.21 & 1.53 \\
\hline 2020 & 14.72 & 2.45 & 16.64 & 1.74 & 11.82 & 0.30 & 2.04 \\
\hline 2030 & 15.24 & 3.55 & 23.20 & 2.44 & 16.01 & 0.43 & 2.82 \\
\hline 2040 & 15.43 & 4.09 & 26.51 & 3.24 & 21.00 & 0.64 & 4.15 \\
\hline 2050 & 15.21 & 4.38 & 28.80 & 3.32 & 21.83 & 1.00 & 6.57 \\
\hline
\end{tabular}


the other hand, they analyzed the impact of aging society on the IT/IS products. Their analysis reached the conclusions: with the three aspects of active works of developing and even creating the elderly's information needs, establishing information systems to cover the elderly users, designing specifically the human--computer interface for the elderly users, and dealing with challenges brought by aging society and seizing the potential industry opportunities.

Jiang lihua, Huang jiacheng (2011) [2] inquired into the information needs of the elderly in city community, considering various information needs, such as information consultant, entertainment information, aging education system information, digital network information, for the aged living in the local community. Accordingly, they determined the priority of information needs from the elderly' and the caregivers' viewpoints and also evaluated the capability of community to satisfy these needs.

Yuan xiaoling, Jia junzhi and Zhu dan (2009) [12] investigated and analyzed village peasant's information demand kinds and methods, finding that peasant information demands are diversified and have focused features. Because of the influence of factors such as information ability, information infrastructure and information organization level, the satisfaction rate of peasant is not high. These authors put forward some measures to better satisfy peasant information demand, including cultivating peasant information self -help ability, providing abundant information acquisition channel and strengthening countryside library construction, etc.

Another example of studying the information needs of rural population is that of Wu piaosheng (2011), who documented a participatory assessment of the information needs of the elderly in Yansan, a rural community in Jiangxi province in Middle-area China. The objective was to assess the information and learning needs of male and female aged in the Yansan community in order to generate information that could assist in planning. The author highlighted the need for governments and development planners to adequately understand the socio-economic circumstances and desires and needs of the aged of different ages in order to plan and implement programs for them effectively. Also, the writer of the paper argued for an in-depth analysis of the information demand, supply and service so as to provide with the theoretical basis for governmental policies in the regard.

Zhang shaochen (2010) and Zhang tao (2011), in their dissertations, talked about aspects of rural information service needs, such as the history of countryside community, their culture, education level, and also library services provision for the aging population before and after the revolution concerning agriculture, rural villages and farmers meaning "three agrarian issues" that have been a big bottleneck for the society development and modernization in China.

Xiao qiong (2009), in his dissertation, intended to present a model for studying which factor significantly relates to the different content and channel of agricultural information service. After conducting the descriptive analysis, the correlation analysis and the Logistic analysis were used to validate the model. In the end, based on the above research, this dissertation analyzed the current status of the rural information service supply and discusses how to build an effective and efficient rural information service system.

The central government of China, considering the information needs and social situations of countryside, has issued several crucial policies to accelerate the informationization process of rural areas and the practice is going on. The proposed model for rural information service have put forward these traits [13]: (1) the information service should be available to the majority of the rural population; (2)the information service should be coordinated with local situations and quotidian life; (3) access to online education should be very easy in rural society; (4) the required manpower for the rural information service should have lasting training; (5) rural information service should provide the same equal communicative media as urban ones.

Liu min, Deng yi cheng, He jing, Liu yue (2011) [14] addressed the subject of culturally benefitting the people, including the elderly people, which has challenged the library circle to rethink the way it delivers services to, and addresses the issues "three agrarian issues" concerning agriculture, farmer and rural village, strengthening excavating the information needs of farmers, Further attaching great importance to the rural informatization and improving the rural information service system. The writers aimed to explore some of the issues surrounding the approaches to rural information service work, with a specific emphasis on actively changing farmers' traditional conservative information idea, strengthening the consciousness of the modern information demand. They concluded that the development of standards relating to rural information service is still in its infancy and heavily dependent upon some traditional medias. The multiplicity of devices has focused standards and best practices upon the convenience aspects of devices and also on an important means to satisfy the information needs of rural population.

With the above literature reviews, the main purpose of this paper is to explore the information needs of the 
elderly population in rural community in Jiangxi province of China. The concrete objectives can be classified as:

(1) Studying their current information accessing situations;

(2) Exploring their required information sources to satisfy their information needs;

(3) Seeking the essential equipment which could help them access information.

\section{Methods}

The target populations of this survey are aged residents in rural community of the Yong Xiu County, 600 respondents being selected as the research population. The survey, which included 14 close-ended questions on a variety of topics, such as essential information needs, demographic characteristics.etc, was distributed among the target populations in questionnaire form after measuring validity and reliability. Because the investigator herself was born there and gave guidance to the informants, they were interested in the questionnaire survey cooperatively and 600 completed questionnaires were returned, giving an overall response rate of 100 percent.

A thorough examination of the relevant literatures has been made to ensure data validity and to further reduce the possibility of non-random errors. Four post graduates majoring information management and information system were asked to review the questionnaire for validity, completeness, and readability. At the same time, inter-item analysis was used to check scales for internal consistency or reliability. Specifically, Cronbach's reliability coefficient was calculated for each scale. The questionnaire used in this survey demonstrated excellent inter-rater reliability (Cronbach $\alpha=0.85$ ). Individually analyzing scale variables, the score varied between 0.842 (reliability) and 0.861 (quality of information).The domains such as "respondent's age" were not scaled and the Cronbach's reliability coefficient could not be calculated. The Cronbach's alpha coefficients for each domain are summarized in Table 2. Descriptive statistics are calculated with the Statistical Package for the Social Sciences (SPSS) (version 13) to obtain the demographic characteristics of the population and frequency of use of information sources, detailed demographic characteristics of these people are given in Table 3.

\section{Results}

Based on the questionnaire responses, a typology of five categories of respondents' information needs with 13 subcategories is established. The five information need categories are: Physiological information, Safe information, Affective information, Respected information, Self-realized information [1]. These categories are identified from the questionnaires and refined throughout the review process to reflect prominent themes from similar studies. The corresponding subcategories and the number and percentage of responses for each category are presented in Table 4.

Most of the respondents thought that information quality, reliability, relevance, and accessibility highly influenced their choice of information sources. Therefore, television, radio, passing from mouth to mouth and local newspaper in traditional media sources are frequently used and mobile sets, A/V material, and Internet in non-traditional media sources are seldom selected.

Analysis of the responses indicates that there is a marked preference for television (50 percent) followed by radio (20 percent), passing from mouth to mouth (18 percent), local newspaper (7 percent) and non-traditional media sources (5 percent), the detailed being in Table 5.

\section{Discussions and Conclusions}

Considering the respondents' attitudes, the need for fundamental information resources is more felt. The major reason for this need may be the lack of sufficient fundamental information resources in their communities. In the elderly' opinion, the fundamental information subjects which take priority in importance are food, clothing, shelter, action, care , healthcare, and pension policy subjects.

These respondents' point of view has implied that the most important feature of a proper information services is its availability, because they think they are almost short of direct information services in their communities, as if they are forgot by the social public. The survey demonstrates that few researchers have been interested in meeting information needs of the elderly and providing information services for this stratum. In consideration of the results acquired through data analysis, reviewing the background and optimizing the elderly' access to information should be widely and quickly thought by researchers and practitioners.

The focus of this survey is the information needs of elderly people in rural communities of Yong Xiu County 
Table 2. Reliability analysis results.

\begin{tabular}{|c|c|c|}
\hline Variables & Measurement Level & Cronbach $c$ \\
\hline age & nominal & -- \\
\hline gender & nominal & -- \\
\hline requirement-level & ordinal & \\
\hline fundamental & nominal & -- \\
\hline \multicolumn{2}{|l|}{ topic } & -- \\
\hline Physiological info & nominal & -- \\
\hline Safe info & nominal & -- \\
\hline Affective info & nominal & -- \\
\hline Respected info & nominal & -- \\
\hline Self-realization info & nominal & -- \\
\hline \multicolumn{3}{|l|}{ Info criteria } \\
\hline Quality of info & scale & 0.861 \\
\hline Reliability & scale & 0.842 \\
\hline Relevance & scale & 0.855 \\
\hline Accessibility & scale & 0.849 \\
\hline Availability & scale & 0.847 \\
\hline Ease use & scale & 0.854 \\
\hline Currency & scale & 0.858 \\
\hline Choice of traditional sources for info & nominal & -- \\
\hline Choice of non-traditional sources for info & nominal & -- \\
\hline Importance of info service & nominal & -- \\
\hline Info-provider characteristics & nominal & -- \\
\hline TV and broadcast availability & scale & 0.859 \\
\hline Communication with others (friends, neighbor) & scale & 0.852 \\
\hline
\end{tabular}

Table 3. Demographic characteristics.

\begin{tabular}{ccc}
\hline Variables & Frequency & Percentage \\
\hline Age (years) & & 21.7 \\
$45<$ age $<55$ & 130 & 49.2 \\
$55<$ age $<65$ & 295 & 24.2 \\
$65<$ age $<75$ & 145 & 4.9 \\
Age $>75$ & 30 & 40.0 \\
gender & & 60.0 \\
male & 240 & 28.3 \\
female & 360 & 31.7 \\
Education level & & 28.3 \\
Non education & 170 & 11.7 \\
Primary school & 190 & \\
middle school & 170 & 70 \\
Senior high school
\end{tabular}


Table 4. Information needs by topic.

\begin{tabular}{crrr}
\hline Category & Subcategory & Frequency & Percentage \\
Physiological & Food, clothing, shelter, action, care information & 320 & 26.7 \\
Safe & Healthcare, pension policy information & 23.3 & 230 \\
Affective & Friends and family activities, club activities information & 190 & 19.2 \\
Respected & Self assessment, social evaluation information & 180 & 15.8 \\
Self-realized & Knowledge skill, job information & 1200 \\
total & & 100.0
\end{tabular}

Table 5. Use frequency of information sources.

\begin{tabular}{cccc}
\hline Sources of Info & Number of Respondents & Percentage & Rank \\
\hline television & 300 & $50 \%$ & 1 \\
radio & 120 & $20 \%$ & 2 \\
mouth to mouth & 108 & $18 \%$ & 3 \\
newspaper & 42 & $7 \%$ & 5 \\
others & 30 & $5 \%$ & 5 \\
\hline
\end{tabular}

in Jiangxi province in China. The insufficient number of investigations focusing on the elderly people' information needs and the results might not be applicable to other groups of the elderly people. Future research should therefore investigate other elderly people' information needs and explore the contingency model for providing information services according to their needs. That conducting a feasibility study on designing digital information exclusively for the elderly in which they can find required information is important.

\section{Acknowledgements}

This work was financially supported by innovation fund project special for graduate students in Jiangxi province (yc2013-b035) and fund project of Humanities and social science special for colleges and universities in jiang xi province (GL1312) and Science and technology project of Jiangxi education commission (GJJ12737).

\section{References}

[1] Zuo, M.Y., Liu, Q.Q. and Liu F. (2009) Study on the Model of the Elderly’s Information Needs: Design and Application. Management Review, 21, 71-77.

[2] Jiang, L.H. and Huang, J.C. (2011) The Demand of the Aged and Livable Community Construction. Journal of east China University of Science and Technology (Social Science Edition), 6, 87-93.

[3] Zhu, X.J. (2012) Aging Society and the Construction of Livable Communities. Social work, 3, 1672- 4828.

[4] Rodriguez, T., Fischer, K. and Kingston, J. (2005) Intelligent Services for the Elderly over the TV. Journal of Intelligent Information Systems, 25, 159-180. http://dx.doi.org/10.1007/s10844-005-0187-X

[5] Murray, J.L. (1989) Health Maintenance: Care of the Ageing Patient. Primary Care, 16, 289-303.

[6] Abdulraheem, I.S. (2005) An Opinion Survey of Caregivers Concerning Caring for the Elderly in Ilorin Metropolis, Nigeria. Public Health, 119, 1138-1144. http://dx.doi.org/10.1016/j.puhe.2005.04.005

[7] Duner, A. and Nordstrom, M. (2005) Intentions and Strategies among Elderly People: Coping in Everyday Life. Journal of Aging Studies, 19, 437-451. http://dx.doi.org/10.1016/j.jaging.2004.10.001

[8] Zhang, Z.C. and Cai, J.X. (2013) The Highlights, Difficulties and Countermeasures on the Implementation of the New Urbanization Strategy in Henan Province. Economic Geography, 33, 53-58.

[9] Kinsella, K. and Velkoff, V.A. (2001) U.S. Census Bureau, Series P95/01-1, An Aging World, 2001. Government Printing Office, Washington DC. 
[10] Jian, B.Y., Dong, H.K. and Jian, L,Q. (2011) Study of New Construction of rural Community Organizations under Point of View Combined Urban and Rural Village. Journal of Gansu Lianhe University (Natural Sciences), 25, 74-76.

[11] Mao, X.O. (2005) Goal-Directed User Study and Design of IT Product for Elders. Dalian Maritime University, Dalian.

[12] Yuan, X.-L., Jia, J.-Z. and Zhu D. (2009) Investigation and Study of Shanxi Province Peasants Information Demand. Information Science, 27, 1194-1198.

[13] Theodorakopoulos, N., Preciado, D.J.S. and Bennett, D. (2012) Transferring Technology from University to Rural Industry within a Developing Economy Context: The Case for Nurturing Communities of Practice. Technovation, 32, 550-559. http://dx.doi.org/10.1016/j.technovation.2012.05.001

[14] Liu, M., Deng, Y.C., He, J. and Liu, Y. (2011) Present Situations of Information Demands of Hunan Rural Area and Its Countermeasure. Library Journal, 30, 44-49. 